\title{
Preparation of High Performance ZSM-5 Zeolite Membranes for CO2/H2 Separation
}

\author{
Seyed Mojtaba Mirfendereski ${ }^{1}$ and Tayebeh Mazaheri ${ }^{2}$ \\ ${ }^{1}$ Arizona State University \\ ${ }^{2}$ Affiliation not available
}

September 10, 2020

\begin{abstract}
High-quality ZSM-5 zeolite membranes were successfully synthesized on the outer surface of tubular $\alpha$-alumina substrates by manipulating the microstructure of the zeolite layer using a new different-sized seeding (DSSM) in combination with variabletemperature/time (VTT) methodd. In this method the microcracks/defects in the primary seed layer are filled by smaller seeds and effectively eliminated using a proper temperature/time profile, resulting in a significant increase in selectivity without scarifying permeance. The effects of number and combination of seed layers, seed size, and synthesis conditions on the microstructure, N2/SF6 gas permeation, and H2/CO2 separation performance of membranes are evaluated in detail. The synthesized ZSM-5 membranes show the microstructure of thin, fully inter-grown, and densified zeolite layer that is responsible for high selectivity without any negative effect on the permeance. The best synthesized defect-free membranes exhibited a very low $\mathrm{H} 2 / \mathrm{CO} 2$ selectivity of 0.1 with $\mathrm{CO} 2$ permeance of $3 \times 10-5$ mol m-2 s- 1 Pa- 1 .
\end{abstract}

\begin{abstract}
High-quality ZSM-5 zeolite membranes were successfully synthesized on the outer surface of tubular $\alpha$ alumina substrates by manipulating the microstructure of the zeolite layer using a new different-sized seeding (DSSM) in combination with variable-temperature/time (VTT) methodd. In this method the microcracks/defects in the primary seed layer are filled by smaller seeds and effectively eliminated using a proper temperature/time profile, resulting in a significant increase in selectivity without scarifying permeance. The effects of number and combination of seed layers, seed size, and synthesis conditions on the microstructure, $\mathrm{N}_{2} / \mathrm{SF}_{6}$ gas permeation, and $\mathrm{H}_{2} / \mathrm{CO}_{2}$ separation performance of membranes are evaluated in detail. The synthesized ZSM-5 membranes show the microstructure of thin, fully inter-grown, and densified zeolite layer that is responsible for high selectivity without any negative effect on the permeance. The best synthesized defect-free membranes exhibited a very low $\mathrm{H}_{2} / \mathrm{CO}_{2}$ selectivity of 0.1 with $\mathrm{CO}_{2}$ permeance of $3 \times 10^{-5} \mathrm{~mol}$ $\mathrm{m}^{-2} \mathrm{~s}^{-1} \mathrm{~Pa}^{-1}$.
\end{abstract}

Keywords: ZSM-5, Zeolite membrane; Different-sized seeding; Variable temperature/time; $\mathrm{CO}_{2}$ selective

\section{Introduction}

Accumulation of carbon dioxide in the atmosphere significantly threatens human life due to its greenhouse effect [1] indicating the importance of the development of efficient separation processes for carbon dioxide removal [2]. MFI-type zeolite membranes due to their high thermal, mechanical, and chemical stabilities, proper hydrophobic properties, and high $\mathrm{CO}_{2}$ adsorption capacity are promising to control $\mathrm{CO}_{2}$ emission [3]. Among MFI-type zeolite membranes, its Al-containing analogue ZSM-5, if supported on porous ceramic tubes are attract for large scale separation of $\mathrm{CO}_{2}$ from gaseous mixtures involved in natural gas, biogas, and flu gas industries [4] due to its unique pore structure, which is similar to many industrially important molecules [5]. 
It is well-known that the performance of a tubular supported zeolite membrane in a gas separation process depends on the quality of the polycrystalline zeolite layer in terms of the number of defects/non-zeolitic pores and the thickness of the zeolite membrane. The former determines the membrane selectivity, while the latter responsible for permeability [6,7]. Therefore, recent works have been focused on the elimination of the defects/non-zeolitic pores and reducing the membrane thickness $[8,9]$. The defects generally form as a result of support defects, expansion mismatch problems, high-temperature heating/cooling cycles, especially during the template removal process, and a non-uniform seed layer [10].

Towards eliminate inter-crystalline gaps in the ZSM-5 zeolite framework, Zhang et al. [11] found that seed size has important effects on the formation of seed layers that determines the quality of regrown zeolite membranes. They showed that the zeolite layer synthesized from small seeds $(100 \mathrm{~nm})$ are more uniform and denser. An increase in seed size $(600 \mathrm{~nm}-1.5 \mu \mathrm{m})$ makes the zeolite layer coarser and the intergrowth of the membranes becomes poorer. Their results showed also that the crystal intergrowth of the membrane improves by increasing synthesis temperature reducing the voids and changing the orientation of crystal growth. Xia et al. [12] systematically manipulated the microstructure of the MFI-type zeolite membranes by tuning the seed size and seed morphology. They showed that small seeds $(<200 \mathrm{~nm})$ tend to form c-oriented zeolite layer, whereas large seeds $(>500 \mathrm{~nm})$ tend to grow in different directions and form more defective layer due to the low space limitation suppression under the same synthesis condition. As a result, small seeds tend to form a continuous, less defective, and dense zeolite layer, while larger seeds usually form a defective porous layer [11]. Shan et al. [13] found that the seeding procedure, as well as the quality/density of the seed layer, greatly influence on the MFI-type zeolite membrane formation and its separation performance. They showed that a continuous and dense zeolite seed layer is necessary to obtain a ZSM-5 membrane with good quality. However, their small seed size $(70 \mathrm{~nm})$ along with high seed concentrations $(>10 \mathrm{wt} . \%)$ led to a thick zeolite layer and caused the membrane to lose its permeability.

Looking from another perspective, Li et al. [14] tried to improve the performance of ZSM-5 zeolite membranes using a two-stage varying-temperature method. According to their method, membrane synthesis begins at $130 @ \mathrm{C}$ for $4 \mathrm{~h}$, synthesis temperature then increases rapidly to $170 @ \mathrm{C}$, and synthesis continues for another $4 \mathrm{~h}$. They demonstrated that compared with synthesis at the constant temperature, this method is very effective for the preparation of high-quality membranes via controlling the rates of nuclei formation and crystal growth by changing the synthesis temperatures. The best ZSM-5 zeolite membrane obtained by Li et al. showed hydrogen permeance of $2.4 \times 10^{-6} \mathrm{~mol} \mathrm{~m}^{-2} \mathrm{~s}^{-1} \mathrm{~Pa}^{-1}$ along with an $\mathrm{H}_{2} / \mathrm{n}$-butane selectivity of 129 . The varying-temperature method was applied also by Kong et al. [15] to prepare thin and continuous MFItype zeolite membranes on disc-shaped $\alpha$-alumina supports. They showed that the inter-crystalline regions can effectively be eliminated using a proper synthesis temperature profile that leads to higher selectivities. However, due to application on unseeded supports, their selectivity ( 22) for the same separation conditions was almost 6 times lower than that of $\mathrm{Li}$ et al. (130). Considering all the above-mentioned facts, to further improve the selectivity of tubular ZSM-5 zeolite membranes, we need to minimize inter-crystalline gaps of the membrane layer via modifying the seeding method and combine it with an appropriate synthesis temperature/time profile. In this study, we report a new secondary-growth synthesis method consisting of multi-layer seeding in combination with the variable temperature/time profiles to prepare high-quality ZSM-5 zeolite membranes on alumina tubular supports. The schematic procedure of our proposed hybrid different-sized seeding / varying-temperature method is shown in Fig. 1.

In this method, three different sized seed particles are coated, fixed, and calcined to the support surface, in order of size. The hydrothermal synthesis process then is carried out under different varying temperature/time profiles. The as-synthesized zeolite membrane would contain a well inter-grown, densified, and uniform top layer which leads to higher selectivity, and a less inter-grown porous bottom layer that leads to higher permeance. This novel hybrid method enhances the selectivity of the tubular ZSM-5 zeolite membrane without sacrificing its permeance via the elimination of the inter-crystalline gaps/defects and decreasing the membrane thickness. 


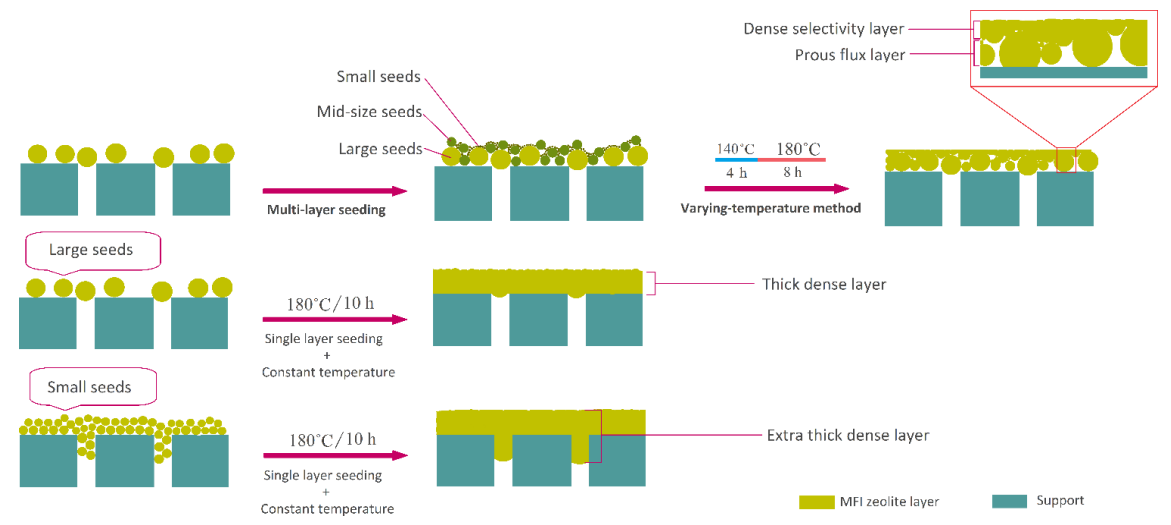

Fig. 1: The schematic procedure of our proposed hybrid different-sized seeding / variable temperature/time method

\section{Experimental}

\subsection{Preparation of alumina tubular support}

The $\alpha$-alumina tubes were prepared using the previously described extruding method [16]. More information about the support characteristics are presented in Table S1 in supplementary information. The SEM image of surface and cross section of support are shown in Fig. S1.

\subsection{Preparation of zeolite ZSM-5 seeds}

The different-sized seeding technique requires zeolite seeds with different particle sizes that can be produced by different procedures. In this study, zeolite ZSM-5 seeds with the size of $60 \mathrm{~nm}, 300 \mathrm{~nm}$ and $1.5 \mu \mathrm{m}$ were prepared with the molar composition of $4 \mathrm{SiO}_{2}$ : TPAOH: $1000 \mathrm{H}_{2} \mathrm{O}$ by adding fumed silica (Sigma-Aldrich, $7 \mathrm{~nm}, 350-440 \mathrm{~m}^{2} \mathrm{~g}^{-1}$ ) and sodium hydroxide (Sigma-Aldrich, 98\%) in tetrapropylammonium hydroxide (Sigma-Aldrich, $1 \mathrm{M}$ ). The mixture was then aged under stirred at room temperature for $24 \mathrm{~h}$ until a clear homogeneous solution was obtained. The seed sizes were controlled by the method developed by Xia et al. [12] that performs by adjustment of the synthesis time program during the synthesis. The solution was then transferred to a Teflon-lined Stainless steel autoclave and placed in an oven set at 140@C. After proper synthesis time $(3 \mathrm{~h}, 5 \mathrm{~h}$, and $14 \mathrm{~h}$ for $60 \mathrm{~nm}, 300 \mathrm{~nm}$, and $1.5 \mu \mathrm{m}$ seeds, respectively), the obtained zeolite seeds were then purified by repeating rinsing and centrifuging processes. The XRD patterns of different size synthesized seeds are presented in Fig. 3, showing that all the seeds used here were pure crystalline with the characteristic peaks of ZSM-5 zeolite. The intensity of characteristic peaks enhanced with the increase of seed size.

\subsection{Synthesis of tubular ZSM-5 membranes}

Up to three layers of ZSM-5 zeolite seeds were coated to the outer surface of the tubular support using the dip-coating technique. One layer has large seeds $(1.5 \mu \mathrm{m})$ as the primary layer, another layer has midsize seeds $(300 \mathrm{~nm})$ as the intermediate layer, and the last layer has small seeds $(60 \mathrm{~nm})$ as the top layer. In order to better cover the support surface, the seed particles were assembled to the support using the cationic linkage technique. In which the positive charge induces to the surface of $\alpha$-alumina support using a coating layer of a proper cationic polymer. The negatively charged seed crystals are adsorbed strongly on the support surface due to the electrostatic interactions and Van der Waals forces [6]. Tubular alumina supports were rinsed first with ethanol and then five times with $0.1 \mathrm{~mol} \mathrm{~L}^{-1} \mathrm{NH}_{3}$ solution. The supports were then immersed in a solution of 2.5 gr PDADMAC [Poly-(diallyldimethylammonium chloride), $20 \mathrm{wt}$. $\%$ in $\mathrm{H}_{2} \mathrm{O}$, Sigma-Aldrich] in $100 \mathrm{~mL} \mathrm{H} 2 \mathrm{O}$ at $60{ }^{\circ} \mathrm{C}$ for $30 \mathrm{~min}$ while stirring. The negative surface charge of the $\alpha$-alumina supports were consequently reversed to positive charge. The positively charged supports were rinsed several times in DI water and dried at ambient temperature overnight. 
The seed suspensions were prepared by mixing of 2-5 g selected ZSM-5 seed with proper particle size, 0.14 g hydroxypropyl cellulose solution (Sigma-Aldrich, $0.5 \mathrm{wt} . \% \mathrm{HPC}, \mathrm{MW}=100000 \mathrm{~g} \mathrm{~mol}^{-1}$ ) as a binder, 94 $\mathrm{mL}$ DI water and followed by reducing the $\mathrm{pH}$ of the solution to 3 by adding a few drops of $1 \mathrm{M} \mathrm{HNO}_{3}$. The positively charged supports were dip-coated with the seed suspension for $5 \mathrm{~min}$ and were then dried for $24 \mathrm{~h}$ under controlled humidity $(40 \%)$ and Temperature $\left(40^{\circ} \mathrm{C}\right)$ to prevent crack formation. The dried seeded supports were then calcined in a two-step calcination process, at $450^{\circ} \mathrm{C}$ for $8 \mathrm{~h}$ and subsequently at $650^{\circ} \mathrm{C}$ for $8 \mathrm{~h}$ with the heating/cooling rate of $20^{\circ} \mathrm{C} \mathrm{h}^{-1}$. The above-mentioned procedure was repeated up to three times entirely using seeds with different particle sizes according to Tables 1-3. Each seeding step was followed by a sequential drying; template-removal; calcination processes. This cycle was conducted to fix the seed particles on the bed layer during each seeding stage.

The ZSM-5 tubular zeolite membranes were synthesized on the outer surface of the alumina tubular support. First, both ends of alumina tubular substrates were sealed by homemade Teflon caps. The molar composition of $5 \mathrm{SiO}_{2}$ : $0.03 \mathrm{Al}_{2} \mathrm{O}_{3}$ : $2.86 \mathrm{NaOH}$ : 0.2 TPAOH: $0.2 \mathrm{TPABr}$ : $693 \mathrm{H}_{2} \mathrm{O}$ was used for preparation of synthesis solution. The initial reaction mixture was prepared by dissolving aluminium sulfate octadecahydrate (Aldrich, $\mathrm{Al}_{2}\left(\mathrm{SO}_{4}\right)_{3} \cdot 18 \mathrm{H}_{2} \mathrm{O}, 98 \mathrm{wt} \%$ ), sodium hydroxide, tetrapropylammonium hydroxide, and tetrapropylammonium bromide (Sigma- Aldrich, TPABr) in DI water, followed by heating under reflux apparatus up to $80 @$ C. Fumed silica was then gradually added into the above solution under vigorous stirring until a clear solution obtained. The mixing under reflux continued in order to perform the aging process for $6 \mathrm{~h}$. The temperature was kept at 80@C during the aging step. The aged solution was then cooled down and transferred into a Teflon-lined stainless-steel autoclave in which the calcined seeded substrates were centered horizontally, in order to obtain a membrane with uniform thickness, using a proper homemade Teflon support.

According to our experiences, in the vertical position, the thickness of the zeolite layer may gradually increase from top to bottom of the membrane especially for long-term synthesis due to the sedimentation of the reaction mixture leaving its footprint on the surface of the membrane.

The hydrothermal synthesis of the ZSM-5 membranes then was conducted at different synthesis temperature/time profiles. In the constant-temperature method (CT), the temperature and time were set to 180@C and $10 \mathrm{~h}$, respectively. Whereas, in the varying-temperature method, they were varied according to Table 5. The synthesized membranes were rinsed, dried overnight at controlled humidity and temperature (40\% and $40^{\circ} \mathrm{C}$, respectively), and then calcined at $450^{\circ} \mathrm{C}$ for $8 \mathrm{~h}$ with a heating and cooling rate of $20^{\circ} \mathrm{C} / \mathrm{h}$ to remove the organic components.

\subsection{Characterization}

The crystallographic properties of the ZSM- 5 seeds and tubular zeolite membranes, were examined using an X-ray diffractometer, XRD (Simense D5000 diffractometer using $\mathrm{Cu} \mathrm{K} \alpha$ radiation $(\alpha=1.54 \AA$ )). The crosssection and surface morphology of ZSM-5 membranes, $\alpha$-alumina tubular supports, and ZSM-5 seeds were evaluated using scanning electron microscopy, SEM (FESEM, Leo, S430i). The Si/Al ratio of the surface and cross-section of the zeolite layer was measured by energy-dispersive X-ray spectroscopy (EDX, Leo, S430i). The average particle size and the particle size distribution of ZSM-5 nano-seeds were characterized by a laser scattering particle analyzer (Zetasizer, Nano-ZS90, Malvern, UK).

The synthesized ZSM-5 tubular zeolite membranes were then mounted into a sealed stainless-steel dead-end special membrane module in order to perform $\mathrm{N}_{2}$ and $\mathrm{SF}_{6}$ single-gas permeation experiments. The gas permeation tests were performed at $25 @ \mathrm{C}$ and a transmembrane pressure range of $100-300 \mathrm{kPa}$. The permeate flux was measured using a bubble flow meter during the gas permeation test. The gas permeances (Eq. 1) and ideal selectivity (the ratio of gas permeances obtained in single-gas permeation tests) were used to determine the quality of prepared membranes. The reported gas permeation data were the mean values of multiple measurements in this study.

$$
\overline{P_{i}=\frac{Q_{i}}{A\left(p_{f}-p_{p}\right)} \quad(1)}
$$


Where $\mathrm{P}_{\mathrm{i}}$ is the permeance of species $\mathrm{i}\left(\mathrm{mol} \mathrm{m}^{-2} \mathrm{~s}^{-1} \mathrm{~Pa}^{-1}\right)$; $\mathrm{Q}_{\mathrm{i}}$ is the gas flow rate at the permeate side $\left(\mathrm{mol} \mathrm{s}^{-1}\right), \mathrm{p}_{\mathrm{f}}$ and $\mathrm{p}_{\mathrm{p}}$ are the feed and permeate pressures $(\mathrm{Pa})$; and $\mathrm{A}$ is the active membrane area $\left(\mathrm{m}^{2}\right)$. The $\mathrm{H}_{2} / \mathrm{CO}_{2}$ binary mixture gas separation tests were performed using the setup shown in Fig. 2. The gas separation experiments were conducted with an equimolar mixture of $\mathrm{H}_{2} / \mathrm{CO}_{2}$ at 25 @ . Permeate and retentate compositions were analyzed using gas chromatography (GC-3800, Varian, TCD detector). The selectivity $(\alpha)$ of membrane was calculated using equations 2 .

$$
\overline{\alpha=\frac{P_{H_{2}}}{P_{\mathrm{CO}_{2}}} \quad(2)}
$$

Where $\mathrm{P}_{\mathrm{i}}$ is the permeance of species i calculated by Eq. 1 .

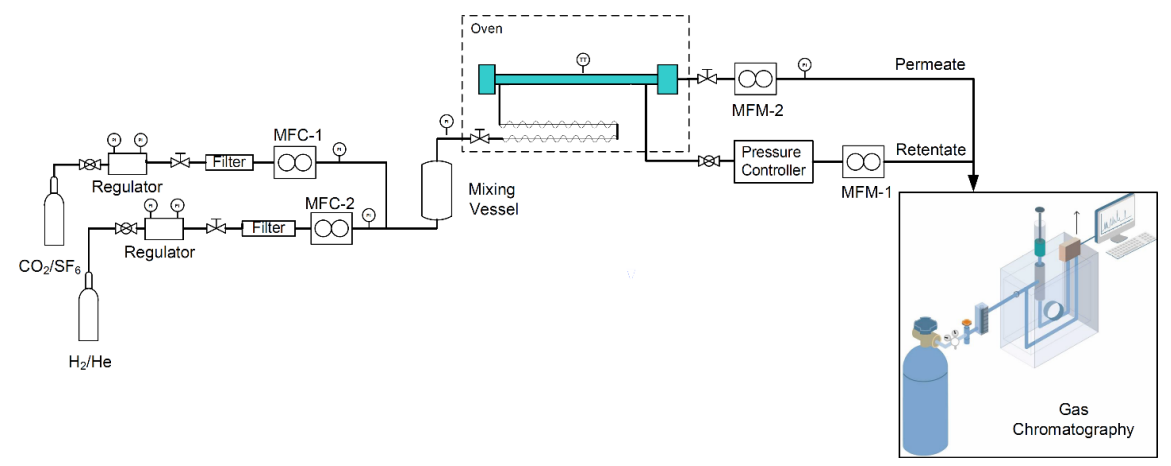

Fig. 2: Schematic of the single and binary gas permeation setup

\section{Results and Discussion}

\subsection{Effect of Multi-Layers Seeds on Membrane Performance}

ZSM-5 zeolite layer was synthesized on the surface of seeded tubular alumina substrates with a seed layer in three different compositions using the secondary growth method. The number and combination of each series are shown in Tables 1-3. Table 1 shows the series SLS samples prepared by a single-layer seeding method using seeds of different sizes. Table 2 shows the series DLS membranes were grown on the two-layer seeded supports using zeolite seeds of different sizes. Table 3 shows the series TLS samples were synthesized by the triple-layer seeding method using three different seed particle sizes. All the samples were subjected to an isothermal secondary growth at $180^{\circ} \mathrm{C}$ for $10 \mathrm{~h}$ and then characterized for morphology/phase-structure gas and permeance/selectivity.

Table 1: ZSM-5 tubular zeolite membranes prepared with one-layer seeding method (SLS)

\begin{tabular}{|c|c|c|c|c|c|}
\hline Sample & Seed size $(\mathrm{nm})$ & $\begin{array}{l}\text { Membrane } \\
\text { thickness }(\mu \mathrm{m})\end{array}$ & $\begin{array}{l}\mathrm{N}_{2} \text { permeance } \\
\left(\mathrm{mol} \mathrm{m}^{-2} \mathrm{~s}^{-1} \mathrm{~Pa}^{-1}\right)\end{array}$ & $\begin{array}{l}\mathrm{SF}_{6} \text { Permeance } \\
\left(\mathrm{mol} \mathrm{m}^{-2} \mathrm{~s}^{-1} \mathrm{~Pa}^{-1}\right)\end{array}$ & $\begin{array}{l}\mathrm{N}_{2} / \mathrm{SF}_{6} \text { Ideal } \\
\text { Selectivity }\end{array}$ \\
\hline $\begin{array}{l}\text { M1 } \\
\end{array}$ & 1500 & 3 & $3.20 \times 10^{-5}$ & $1.27 \times 10^{-5}$ & 2.52 \\
\hline M2 & 300 & 3 & $2.30 \times 10^{-5}$ & $6.85 \times 10^{-6}$ & 3.36 \\
\hline M3 & 60 & 5 & $2.10 \times 10^{-5}$ & $2.50 \times 10^{-6}$ & 8.4 \\
\hline
\end{tabular}

Table 2: ZSM-5 tubular zeolite membranes prepared with dual-layer seeding method (DLS) 


\begin{tabular}{llllll}
\hline & $\begin{array}{l}\text { Top/bottom } \\
\text { layer seed sizes } \\
(\mathrm{nm})\end{array}$ & $\begin{array}{l}\text { Membrane } \\
\text { thickness }(\mu \mathrm{m})\end{array}$ & $\begin{array}{l}\mathrm{N}_{2} \text { permeance } \\
\left(\mathrm{mol} \mathrm{m}^{-2} \mathrm{~s}^{-1} \mathrm{~Pa}^{-1}\right)\end{array}$ & $\begin{array}{l}\mathrm{SF}_{6} \text { Permeance } \\
\left(\mathrm{mol} \mathrm{m}^{-2} \mathrm{~s}^{-1} \mathrm{~Pa}^{-1}\right)\end{array}$ & $\begin{array}{l}\mathrm{N}_{2} / \mathrm{SF}_{6} \text { Ideal } \\
\text { Selectivity }\end{array}$ \\
\hline Sample & $300-1500$ & 4 & $4.70 \times 10^{-6}$ & $8.83 \times 10^{-8}$ & 53.2 \\
M5 & $60-1500$ & 6 & $3.20 \times 10^{-6}$ & $2.82 \times 10^{-8}$ & 100.5 \\
M6 & $300-300$ & 5 & $1.40 \times 10^{-6}$ & $1.92 \times 10^{-8}$ & 72.8 \\
M7 & $60-300$ & 6 & $8.20 \times 10^{-7}$ & $5.01 \times 10^{-9}$ & 163.8 \\
\hline
\end{tabular}

Table 3: ZSM-5 tubular zeolite membranes prepared with triple-layer seeding method (TLS)

\begin{tabular}{|c|c|c|c|c|c|}
\hline \multirow[b]{2}{*}{ Sample } & \multicolumn{5}{|c|}{ Top/middle/bottom } \\
\hline & $\begin{array}{l}\text { layer seed size } \\
(\mathrm{nm})\end{array}$ & $\begin{array}{l}\text { Membrane } \\
\text { thickness }(\mu \mathrm{m})\end{array}$ & $\begin{array}{l}\mathrm{N}_{2} \text { permeance } \\
\left(\mathrm{mol} \mathrm{m}^{-2} \mathrm{~s}^{-1} \mathrm{~Pa}^{-1}\right)\end{array}$ & $\begin{array}{l}\mathrm{SF}_{6} \text { Permeance } \\
\left(\mathrm{mol} \mathrm{m}^{-2} \mathrm{~s}^{-1} \mathrm{~Pa}^{-1}\right)\end{array}$ & $\begin{array}{l}\mathrm{N}_{2} / \mathrm{SF}_{6} \text { Ideal } \\
\text { Selectivity }\end{array}$ \\
\hline M8 & $300-300-1500$ & 7 & $2.05 \times 10^{-6}$ & $1.40 \times 10^{-8}$ & 146.3 \\
\hline M9 & $60-300-1500$ & 7 & $1.80 \times 10^{-6}$ & $6.48 \times 10^{-9}$ & 262.5 \\
\hline M10 & $300-300-300$ & 8 & $4.20 \times 10^{-7}$ & $2.16 \times 10^{-9}$ & 194.6 \\
\hline M11 & 60-300-300 & 10 & $3.10 \times 10^{-7}$ & $1.14 \times 10^{-9}$ & 270.9 \\
\hline M12 & $60-60-300$ & 12 & $2.30 \times 10^{-7}$ & $7.75 \times 10^{-10}$ & 296.8 \\
\hline
\end{tabular}

The SEM images of surface and cross-section of the bare and the seeded tubular $\alpha$-alumina supports are shown in Fig. 3. As can be seen in Fig. 3b, the surface of support was not fully covered by the $1.5 \mu \mathrm{m}$ coffin shape zeolite seeds. However, the second layer of $300 \mathrm{~nm}$ sphere shape seeds (Fig. 3c) significantly covers the gaps and spaces between large seeds at the bottom layer. The third $60 \mathrm{~nm}$ sphere shape seed layer (Fig. 3d) ultimately prepares a smooth, uniform, and defect-free seed layer. The average seed particle size and the seed size distribution of each seed layer are also shown in Fig. 3. As can be seen, the seeds prepared in this study displayed average particle sizes of $1.5 \mu \mathrm{m}, 300 \mathrm{~nm}$, and $60 \mathrm{~nm}$ for the bottom, intermediate, and top layers, respectively. The narrow particle size distribution curves also prove that the adjustment of seed size by controlling synthesis time was performed successfully. The XRD patterns of different size synthesized seeds are presented in Fig. 3f. The patterns indicate that all the seeds used in this study were pure crystalline with the characteristic peaks of ZSM-5 zeolite. The intensity of characteristic peaks enhanced with the increase of seed size. 

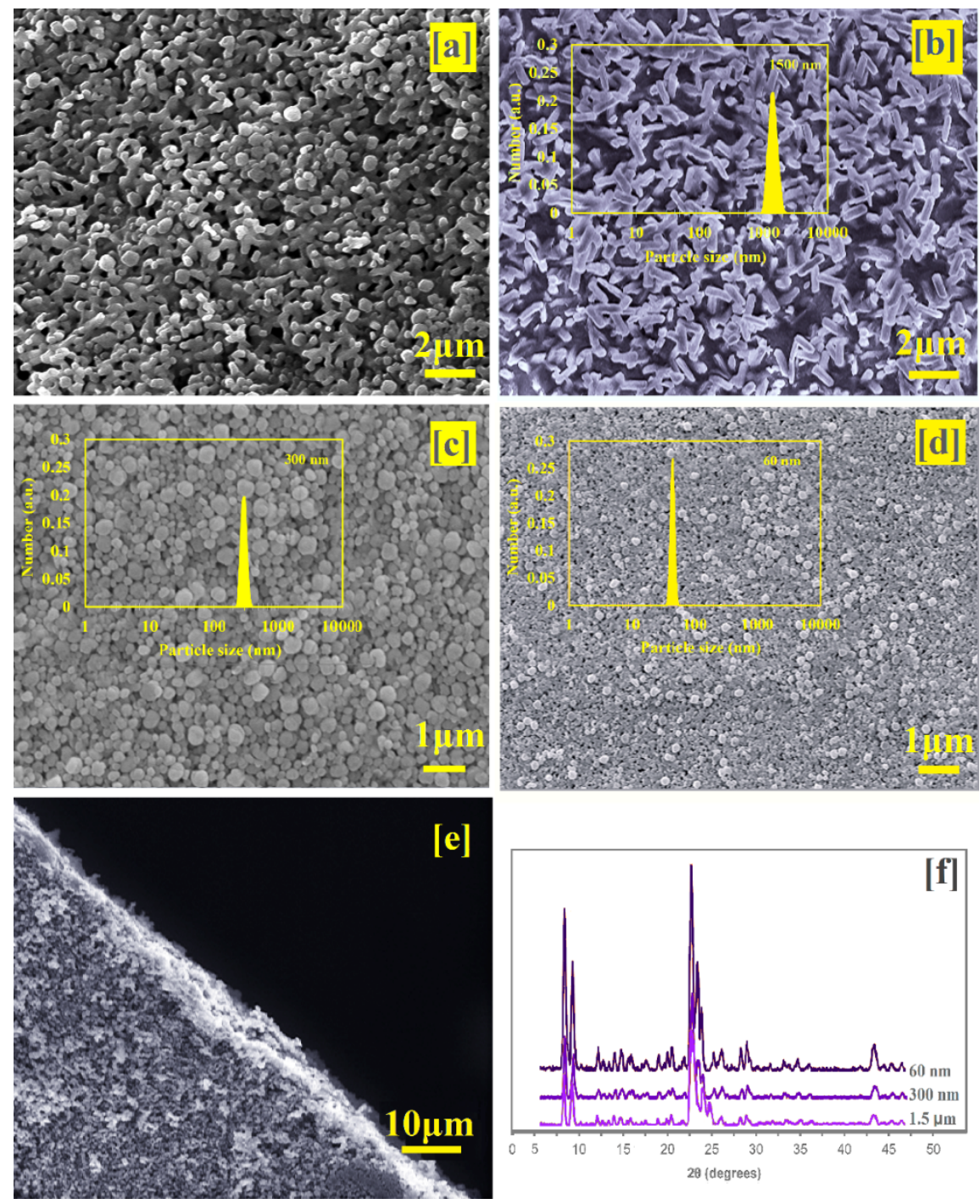

Fig. 3: SEM images and particle size distributions of the bare support surface (a), seeded support surface by $1.5 \mu \mathrm{m}$ (b), $300 \mathrm{~nm}$ (c), and $60 \mathrm{~nm}$ (d) ZSM-5 zeolite seeds. The SEM cross-section of seeded support (e), and the XRD patterns of three different sized ZSM-5 seeds (f) are also available

The XRD patterns and SEM images of surface and cross-section of five typical membranes of series SLS, DLS, and TLS are shown in Fig. 4. The SEM micrographs and XRD's of all other samples are also available in the supplementary information (Figures S2 and S3). The membrane thickness was estimated using SEM images and reported in Tables 1-3. It is clearly observed that the tubular supported zeolite membranes synthesized with different combination of seed layers all reflect the diffraction peaks of the ZSM- 5 zeolite. Indicating that they contain pure ZSM-5 phase and the ratio of $\left(\begin{array}{lll}1 & 0 & 1\end{array}\right)$ and $\left(\begin{array}{lll}0 & 2 & 0\end{array}\right)$ peak show that the zeolite crystals in the membrane are almost c-oriented [17]. Furthermore, the strong peaks of alumina supports in the membranes confirm that the zeolite layers are rather thin. The peak intensity ratio of the ZSM-5 zeolite layer to that of alumina support indicates the crystallinity and consequently the thickness of the zeolite layer.

The SEM images in Figures 4 and S2 show that the membranes synthesized with $300 \mathrm{~nm}$ seeds at the primary layer, (samples M10, M11, and M12 in TLS series) are c-oriented with column-shaped grain crystals. The 
microstructures of these membranes are different from those synthesized by large seeds $(1.5 \mu \mathrm{m})$ at the primary layer. The XRD results in Figures 4 and S3 are also in good accordance with the SEM analysis in which the higher the intensity ratio of the $\left(\begin{array}{lll}1 & 0 & 1\end{array}\right)$ peak to that of the $\left(\begin{array}{lll}0 & 2 & 0\end{array}\right)$ peak $\left(\mathrm{I}_{101} / \mathrm{I}_{020}\right)$, the higher c-oriented degree of the membrane [18].

This special crystal orientation can be ascribed to the density of seeds at the support surface so that higher seed density of small crystals leads to higher space limitation suppression forcing for the growth of seeds along the direction perpendicular to the support surface [19]. The same explanation can be relied on for comparing the membrane thickness. The results in Tables 2 and 3 show that the thickness of the membranes with small seeds $(60 \mathrm{~nm})$ at the top layer is higher than those synthesized using mid-size seeds $(300 \mathrm{~nm})$ at the top layer. 

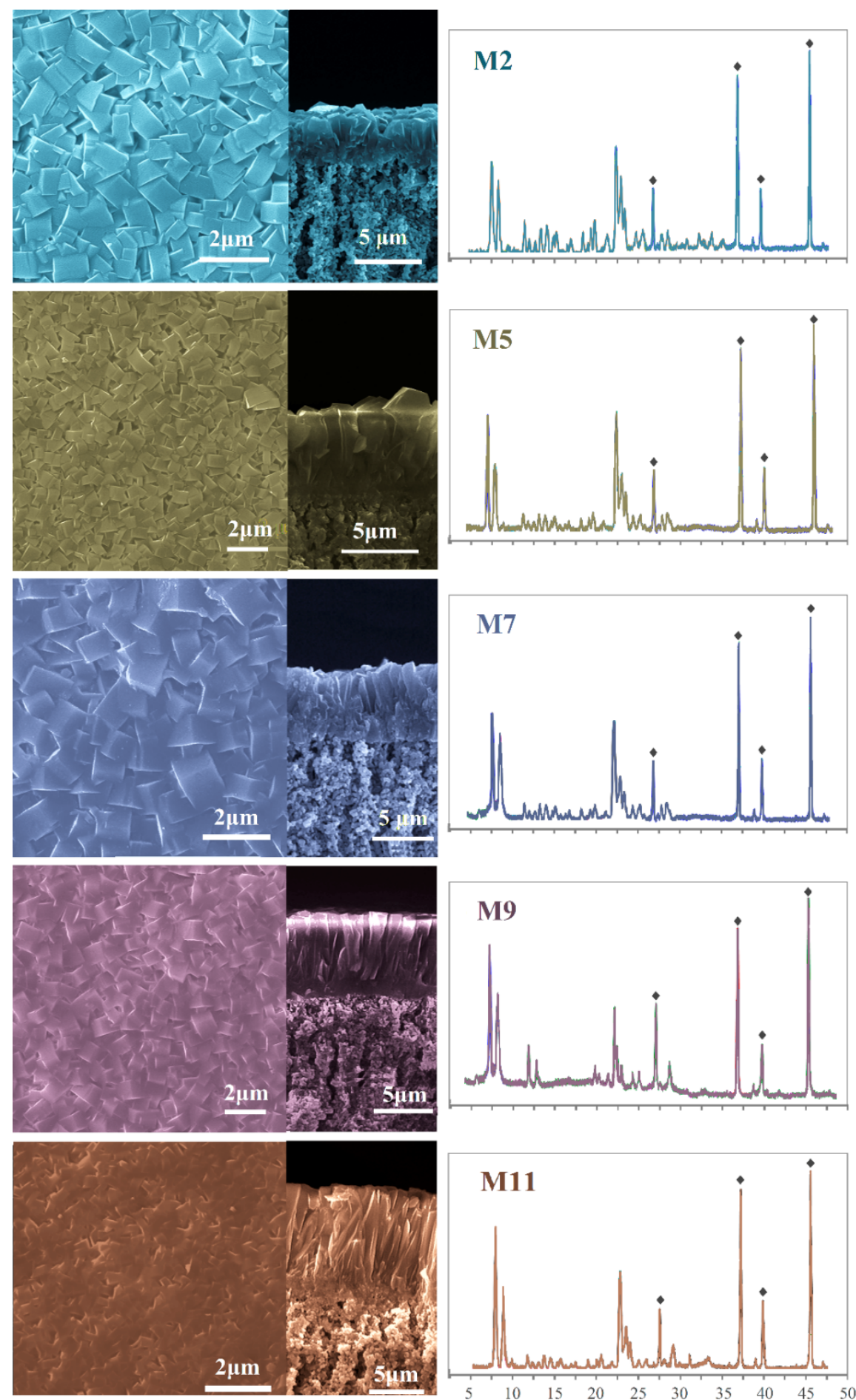

Fig. 4: SEM images and XRD patterns of ZSM-5 zeolite membranes synthesis by one-layer (Series SLS, M2), Dual-layer (Series DLS, M5 and M7) and Triple-layer (Series TLS, M9 and M11) seeding methods, () are from the alumina substrate peaks

This is due to the fact that large seeds accumulate less in density at the top layer, resulting to form larger 
gaps and lower space limitation suppression. This allows large seeds to grow in different directions with a slower rate than that of small seeds [11]. While, the small seeds, due to their lower inter-crystalline gaps, mainly grow along the direction perpendicular to the support surface with a fast growth rate resulting in the thicker zeolite layer [14]. It can be concluded that the seed size at the top layer determines the final thickness of the membrane. The SEM images in Figures 4 and S2 indicate also that the membranes in TLS series have more uniform and smooth surfaces than those in DLS and SLS series. In fact, intergrown of the penetrated small seeds from the top layer into the spaces and inter-crystalline gaps at the bottom layer densifies the density of the zeolite layer resulting in the more uniform and continuous membrane surface.
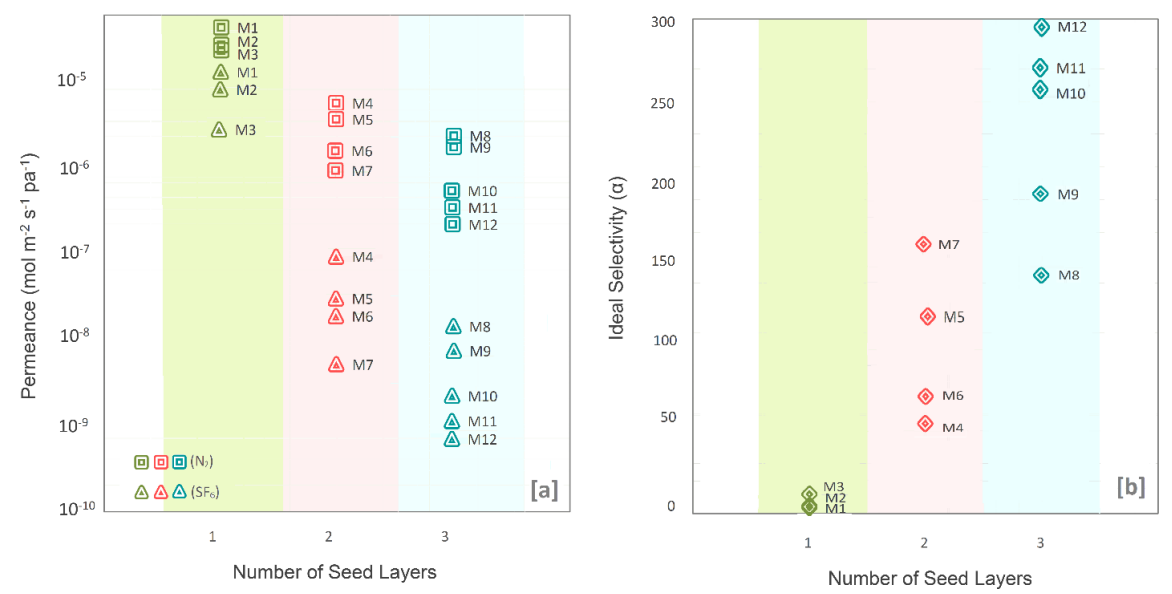

Fig. 5: Effect of different different-sized seeding methods on (a) permeance and (b) ideal selectivity of tubular supported ZSM-5 zeolite membranes

The effects of different-sized seeding method on the performance of ZSM-5 zeolite membranes were evaluated by $\mathrm{N}_{2}$ and $\mathrm{SF}_{6}$ pure gas permeation. The $\mathrm{N}_{2} / \mathrm{SF}_{6}$ permeance and ideal selectivity are widely used as an indicator of membrane quality due to their significant difference in the kinetic diameter $(0.36 \mathrm{~nm}$ and 0.55 $\mathrm{nm}$ for $\mathrm{N}_{2}$ and $\mathrm{SF}_{6}$, respectively) [12]. The permeance and ideal selectivity of the synthesized membranes are shown in Fig. 5. The results in Tables 1-3 and Fig. 5b indicate that the single-layer seeded membranes have low $\mathrm{N}_{2} / \mathrm{SF}_{6}$ ideal selectivities due to the poor intergrowth between zeolite crystals which results in creating more defects and non-zeolitic pores. Membranes with dual-layer seeds (DLS series) and triple-layer seeds (TLS series) show significantly higher selectivities confirming the positive effect of using different-sized seeding method in which the small seeds can effectively penetrate from the top seed layer into the gaps of the bottom layer, grow faster regarding both mass and diameter, and fill the defects during the hydrothermal synthesis process [14].

The results in Fig. 5b reveals that adding the second and third seed layers to the top of the primary seed layer significantly affects the membrane permeance. For example, $\mathrm{N}_{2} / \mathrm{SF}_{6}$ selectivities increase by $2100 \%$ and 230 $\%$ by adding the second and third seed layers, respectively, while the average of $\mathrm{N}_{2}$ permeances diminishes by only $90 \%$ and $65 \%$ at the same condition (Fig. 5a). These results confirm that using the different-sized seeding method significantly enhances the membrane performance if both permeance and selectivity took into consideration.

A closer examining the changing trend of permeance versus seed size at the bottom layer (Fig. 5a) discloses that increasing the seed size in the bottom layer from $300 \mathrm{~nm}$ to $1.5 \mu \mathrm{m}$, if the size of smaller seeds at the top layers are kept constant, significantly increases the permeance by an average of $480 \%$, while the selectivity decreases by only less than $30 \%$. It is due to the fact that using larger seeds at the bottom layer (preferably larger than the pore size of the support), significantly decreases the penetration of seeds into the pores resulting in a reduction in effective membrane thickness and mass transfer resistance. These results also reveal that the seed size at the bottom layer mainly controls the membrane permeance. On the contrary, 
results in Fig. 5a and b indicate that the $\mathrm{N}_{2} / \mathrm{SF}_{6}$ ideal selectivity increases by $230 \%$ and $160 \%$ versus seed size change from $300 \mathrm{~nm}$ to $60 \mathrm{~nm}$ at the top seed layer for DLS and TLS series, respectively. These results confirm that the seed size at the top layer mainly determines the membrane selectivity.

The effect of using a mid-size intermediate seed layer between the large seed layer at the bottom and the small seed layer at the top can be identified by comparison between performances of M5 and M9 membranes. Where using a $300 \mathrm{~nm}$ intermediate seed layer increases selectivity up to $260 \%$, while decreases the $\mathrm{N}_{2}$ permeance by $40 \%$ showing that a proper intermediate seed layer can improve membrane permeance, if the difference between seed sizes in the bottom and top layers is considerable.

During the different-sized seeding process, small seeds from the top layer penetrate into the inter-crystalline gaps/defects between large seeds in the bottom layer. Afterward, because of their higher growth rate compare to large seeds, small seeds effectively fill the gaps/defects during the hydrothermal synthesis, resulting in higher selectivities for membranes in series TLS and DLS than that of series SLS. Consequently, the reduction in seed size in the top layer, reduces the inter-crystalline gaps and makes the zeolite layer denser on the one hand, and increase the membrane thickness via increasing the penetration of seeds into the support pores, on the other hand. The former enhances selectivity and the latter decreases permeance. So, we need to find an optimum combination of seed sizes in the bottom and top layers to maximize the perm-selectivity of the membranes.

Fig. 6 plots $\mathrm{N}_{2} / \mathrm{SF}_{6}$ ideal selectivity versus $\mathrm{N}_{2}$ permeance for series SLS, DLS, and TLS membranes. It can be observed in Fig. 6 that series TLS membranes locate in high selectivity/low permeance region, while series DLS membranes locate in moderate selectivity/permeance region. Considering the results in Fig. 6, we selected the M9 membrane (from series TLS) for further modification using the variable-temperature/time method. The advantages of the new different-sized seeding method can be summarized in Table 4 .

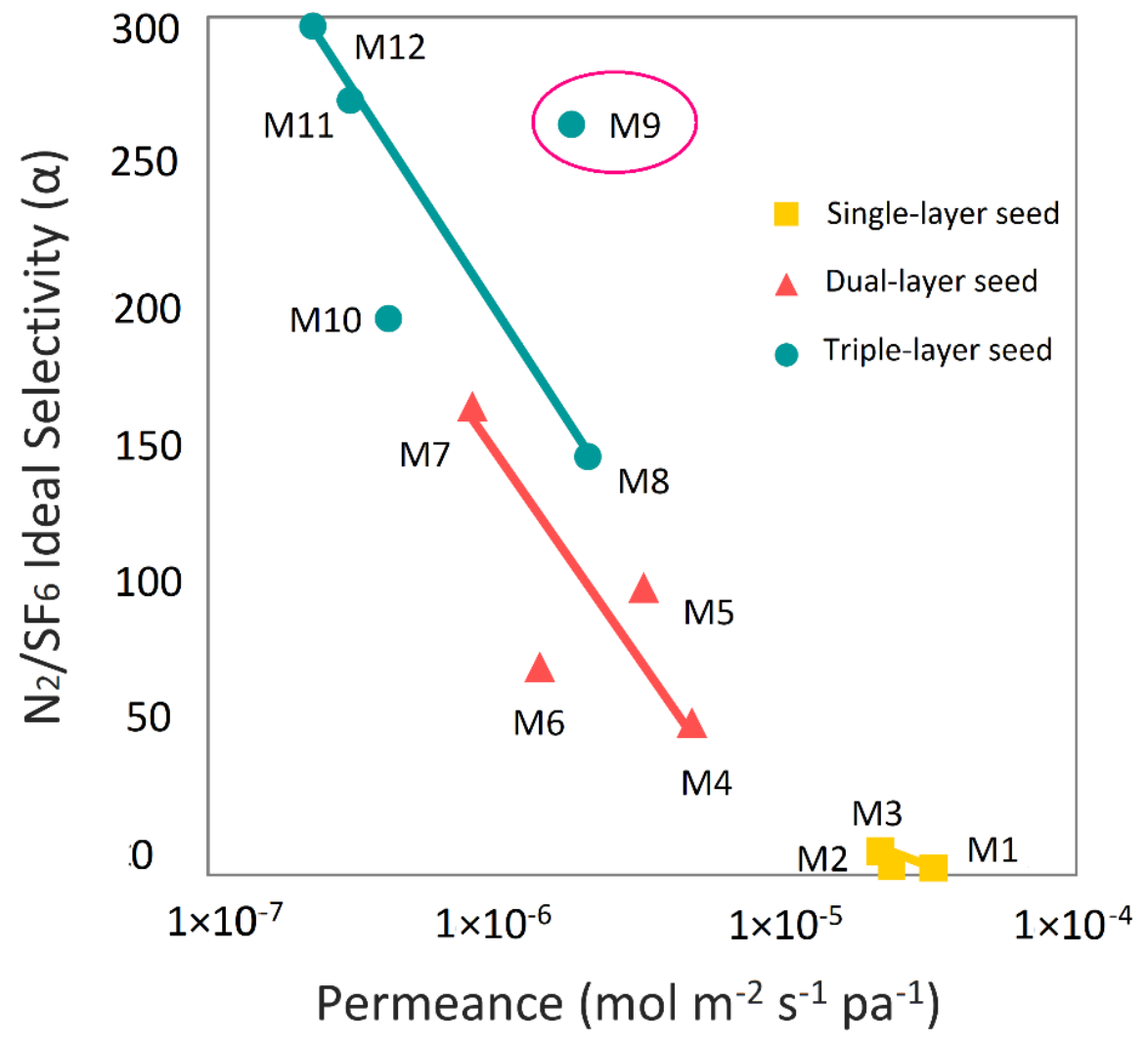


Fig. 6: Ideal selectivity vs $\mathrm{N}_{2}$ permeance for three series of SLS, DLS, and TLS

Table 4: Advantages of the different-sized seeding method

\begin{tabular}{|c|c|}
\hline & Action \\
\hline Using the large seeds as the bottom layer & $\begin{array}{l}\text { Prevents the infiltration of seeds into th } \\
\text { Forms more inter-crystalline gaps in the }\end{array}$ \\
\hline Seed size change at the bottom layer mostly influences the membrane permeance & Seed size change at the bottom layer $m$ \\
\hline Using the small seeds as the top layer & $\begin{array}{l}\text { Small seeds from top layer penetrate in } \\
\text { Forms a uniform thin seed layer at the } \\
\text { Increases the grow rate of small seeds o }\end{array}$ \\
\hline Seed size change at the top layer mostly influences the membrane selectivity & Seed size change at the top layer most \\
\hline
\end{tabular}

\subsection{Effect of Variable-Temperature/Time Method}

The microstructure of the ZSM-5 zeolite layer on the surface of tubular alumina supports was controlled by changing the synthesis temperature/time profile. Based on the fact that low and high temperatures favor nucleation and crystal growth, respectively [11, 20], experiments on secondary growth of the best prepared membrane (sample M9) under the six different temperature/time profiles were conducted in order to identify optimum synthesis conditions for obtaining high quality ZSM-5 zeolite membranes.

According to the literature $[15,21,22]$ the growth rate of ZSM-5 crystal is too low to form the compact zeolite layer on the support surface at temperatures less than $130^{\circ} \mathrm{C}$. Even though prolonging the crystallization time can increase the degree of crystal growth reactions, the membranes synthesized at low temperatures are still defective and show low selectivities. Li et al. [23] showed that to achieve only $60 \%$ zeolite yield in the synthesis of the ZSM-5 zeolite membrane, the synthesis time should be prolonged up to $70 \mathrm{~h}$ and $31 \mathrm{~h}$ for synthesis temperatures of 80 and $100 @ \mathrm{C}$, respectively. Contrarily, Zhang et al. [24] showed that the permeance of ZSM-5 zeolite membranes synthesized at temperatures higher than $180^{\circ} \mathrm{C}$ is drastically reduced. They suggest that ZSM- 5 membranes synthesized at $180^{\circ} \mathrm{C}$ show the highest separation performance for separation of organic/water mixture. The synthesis temperature can also affect the crystallographic planes of zeolite crystal. The growth of ZSM-5 crystal is anisotropic with each crystal orientation exhibiting different growth rates. Wong et al. [25] showed that the highest intensity ratio of $\left(\begin{array}{lll}1 & 0 & 1\end{array}\right) /\left(\begin{array}{lll}2 & 0 & 0\end{array}\right)$ peaks forms in the range of 135-150@C. Consequently, more oriented zeolite layers may be formed. In two other works, Kong et al. $[15,26]$ found that the best temperature range for the synthesis of ZSM- 5 zeolite membranes is 130-170@C. Therefore, the synthesis temperature range of $140-180 @ \mathrm{C}$ was chosen to investigate the effects of varyingtemperature/time method in this study. Table 5 represents the synthesis conditions and performances of membranes prepared by the variable-temperature/time methods.

Table 5: Effect of using the variable-temperature/time profiles on the performance of ZSM-5 membrane (the M9 membrane were selected as the control sample)

\begin{tabular}{llllll}
\hline Sample & $\begin{array}{l}\text { Temperature/time } \\
\text { profile }\end{array}$ & $\begin{array}{l}\mathrm{N}_{2} \text { permeance } \\
\left(\mathrm{mol} \mathrm{m}^{-2} \mathrm{~s}^{-1} \mathrm{~Pa}^{-1}\right)\end{array}$ & $\begin{array}{l}\mathrm{SF}_{6} \text { Permeance } \\
\left(\mathrm{mol} \mathrm{m}^{-2} \mathrm{~s}^{-1} \mathrm{~Pa}^{-1}\right)\end{array}$ & $\begin{array}{l}\mathrm{N}_{2} / \mathrm{SF}_{6} \text { Ideal } \\
\text { Selectivity }\end{array}$ & $\begin{array}{l}\text { Membrane } \\
\text { thickness }(\mu \mathrm{m})\end{array}$ \\
\hline M9 & $\left(\frac{180 C}{10 h}\right)$ & $1.80 \times 10^{-6}$ & $6.48 \times 10^{-9}$ & 262.5 & 7 \\
M13 & $\left(\frac{140 C}{2 h}\right)\left(\frac{180 C}{10 h}\right)$ & $1.72 \times 10^{-6}$ & $6.11 \times 10^{-9}$ & 268.1 & 10 \\
M14 & $\left(\frac{140 C}{4 h}\right)\left(\frac{180 C}{8 h}\right)$ & $2.80 \times 10^{-6}$ & $1.18 \times 10^{-8}$ & 281.4 & 6 \\
M15 & $\left(\frac{140 C}{8 h}\right)\left(\frac{180 C}{6 h}\right)$ & $3.10 \times 10^{-6}$ & $5.56 \times 10^{-9}$ & 223.4 & 5 \\
M16 & $\left(\frac{140 C}{12 h}\right)\left(\frac{180 C}{4 h}\right)$ & $7.37 \times 10^{-6}$ & $9.82 \times 10^{-9}$ & 101.9 & 3 \\
M17 & $\left(\frac{140 C}{16 h}\right)\left(\frac{180 C}{4 h}\right)$ & $4.86 \times 10^{-6}$ & $6.55 \times 10^{-9}$ & 158.8 & 4 \\
\hline
\end{tabular}


* The profile is defined as; initial temperature/time - final temperature/time

The XRD patterns of synthesized membranes listed in Table 5 are shown in Fig. 7. These patterns indicate high crystallinity of zeolite ZSM-5 formed on the surface of tubular alumina supports. As expected, starting the synthesis at low temperature reinforces the nucleation reactions against the crystal growth reactions. So, a larger number of nuclei are produced. In the following, increasing temperature, immediately, shifts the dominant reactions from nucleation to growth reactions. So, at the end of synthesis, a larger number of smaller crystals compared to those formed in isothermal synthesis, are produced. It may also reduce the thickness of the zeolite layer, but, produce a more integrated and uniform layer with eliminated intercrystalline gaps. The results confirm that for a constant total synthesis time, the longer the exposure time to higher temperatures, the higher the crystallinity, the thicker the zeolite layer, and less inter-crystalline gaps. 

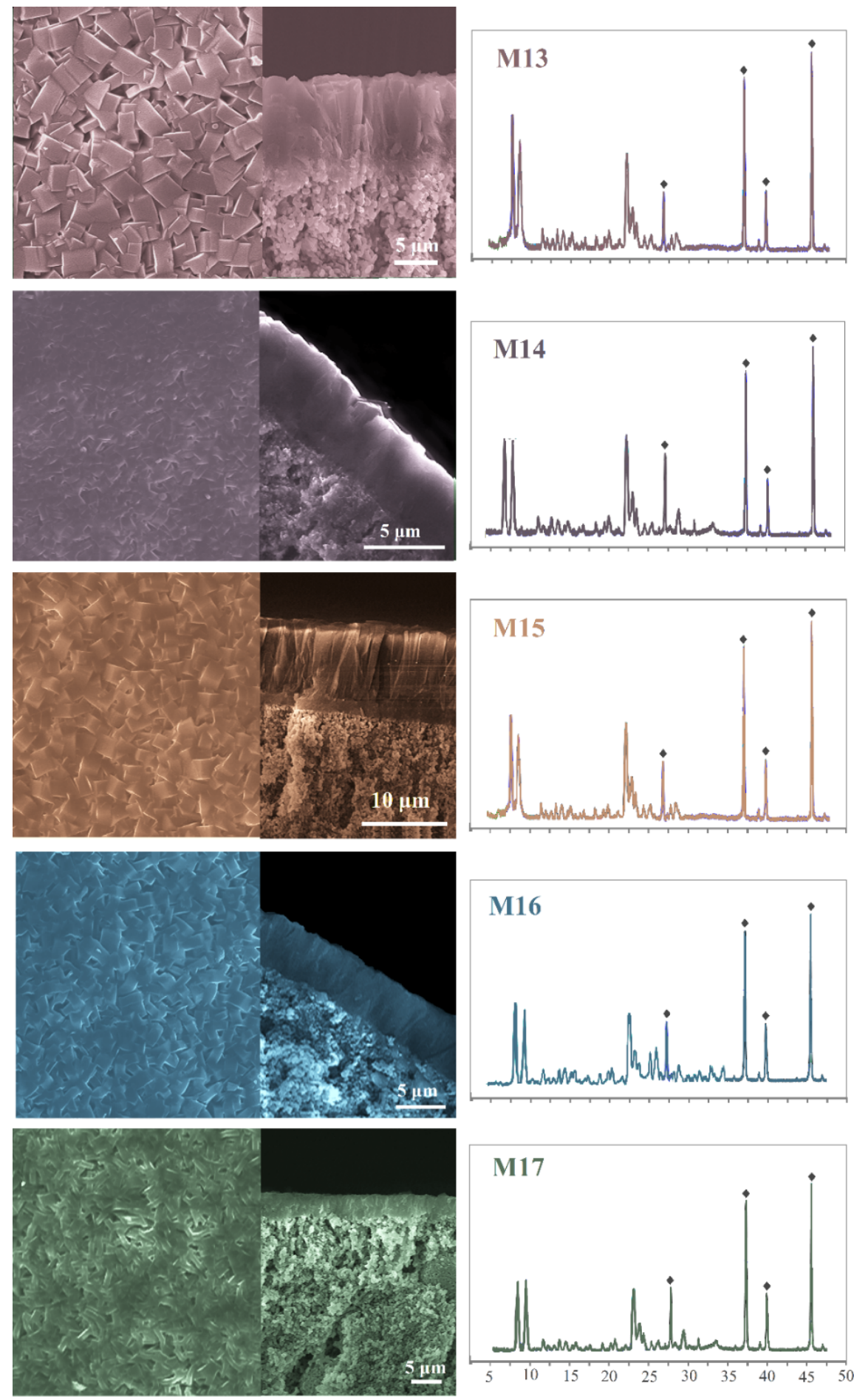

Fig. 7: SEM micrographs of surface and cross-section, and XRD patterns of ZSM-5 zeolite membranes prepared by variable temperature/time profile, () are from the alumina substrate peaks

The surface and cross-sectional SEM images of synthesized membranes listed in Table 5 are shown in Fig. 7. Results in Table 5 and fig. 7 reveal that the membranes synthesized at lower initial temperatures have 
relatively thinner zeolite layer compared to those synthesized at constant temperature. It can be ascribed to the domination of nucleation reactions at the low initial temperature of $140 @ \mathrm{C}$. The produced zeolite nuclei can penetrate into the spaces between fixed zeolite seeds in the top, intermediate and bottom layers. Their higher growth rate compared to that of larger seeds at the high temperature (180@C) stage effectively fills the non-zeolitic pores and defects resulting in a dense and uniform zeolite layer [27].

The SEM images in Fig. 7 demonstrate the different microstructures of the M16 and M17 membranes, in which lower intergrown zeolite framework, higher roughnessw and some micron-sized gaps can be observed on the surface of membranes. It could be due to long-term synthesis at low temperatures and subsequent short-term synthesis at high temperatures resulting in the production of a larger number of small crystals. This confirms the fact that the longer residence time at higher temperatures results in larger crystals, thicker zeolite layers, and a more continuous and denser zeolite layer. It can be also observed in Fig. 7 that the membranes M14 and M15 exhibit more uniform and continuous zeolite films via their optimum synthesis temperature/time profiles. The membranes (M9 and M13) synthesized at high temperature (180@C) for 10 $\mathrm{h}$, show thicker zeolite layer and rougher surface due to the domination of the growth reactions over the nucleation reaction via longer exposure at high temperature at final stage.

$\mathrm{N}_{2}$ and $\mathrm{SF}_{6}$ permeances and $\mathrm{N}_{2} / \mathrm{SF}_{6}$ ideal selectivity of all the synthesized membranes are shown in Table 5 and Fig. 8. The results in Fig. 8 show that the ZSM-5 membranes synthesized at the prolonged low initial temperature $(140 @ \mathrm{C})$, if the duration of the final stage remains constant ( $8 \mathrm{~h}$ at $180 @ \mathrm{C})$, have higher $\mathrm{N}_{2} / \mathrm{SF}_{6}$ ideal selectivities than those synthesized at a short-term low-temperature initial stage, confirming the influence of the nucleation process on improving the selectivity of the final zeolite membranes. The effectiveness of low-temperature initial stage can be approved also by comparing the results of M16 and M17, in which a $4 \mathrm{~h}$ increase in the duration of the initial stage, enhances the selectivity up to $50 \%$. Therefore, the high selectivity of the M14 membrane shows that an initial $4 \mathrm{~h}$ synthesis at 140@C significantly improves the membrane quality via the formation of enough nuclei that grow faster during the final stage $(8 \mathrm{~h}$ at $180 @ \mathrm{C})$ resulting in a well-intergrown zeolite layer. However, prolonging the low-temperature initial stage up to $8 \mathrm{~h}$ simultaneously with shortening the final stage to $6 \mathrm{~h}$ (M15 membrane) drastically decreases the selectivity, showing that the $6 \mathrm{~h}$ synthesis at high temperature $(180 @ \mathrm{C})$ is not enough to form a complete and uniform zeolite layer. The low selectivities of M16 and M17 in Fig. 8 reveal also that the high-temperature synthesis time should be longer than $6 \mathrm{~h}$ to achieve selectivities higher than 200 . 


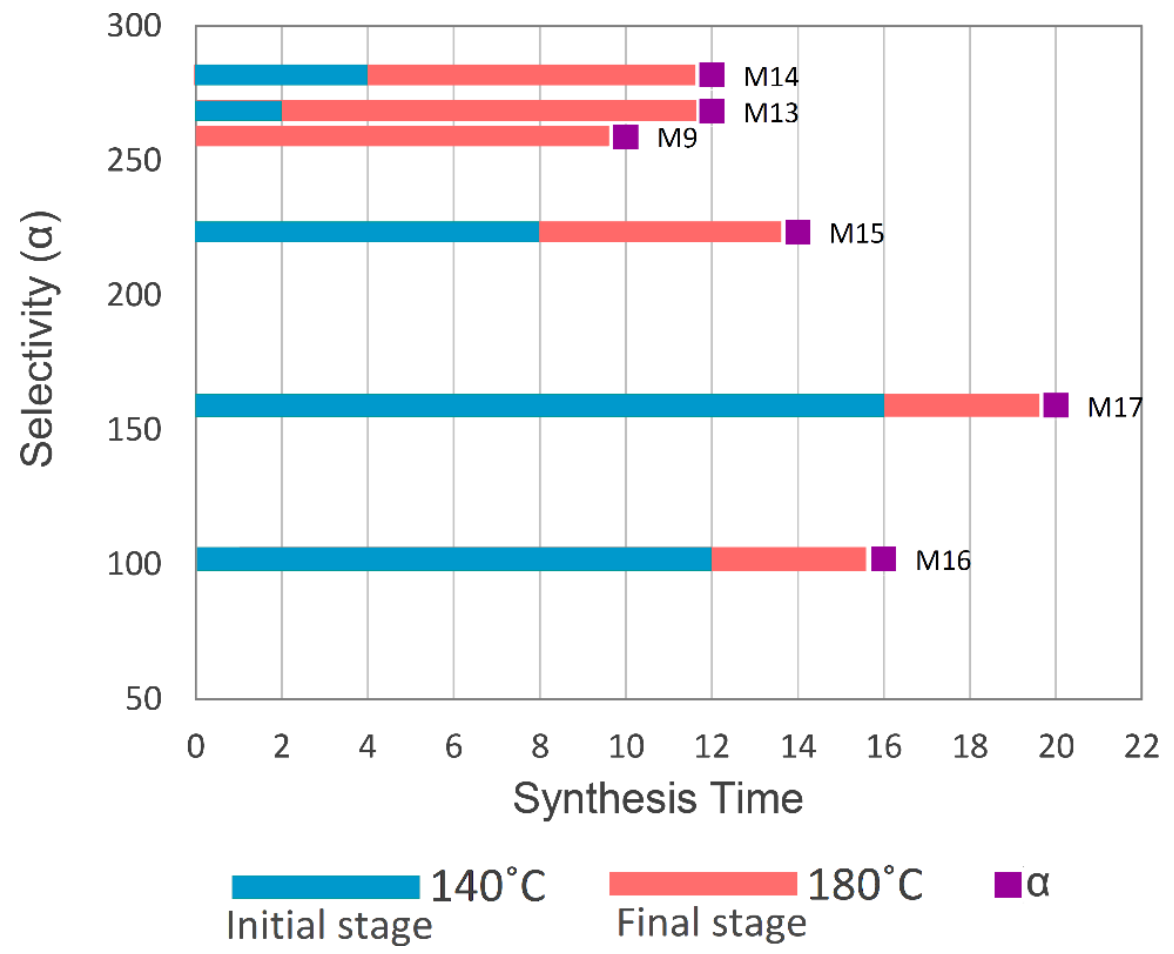

Fig. 8: Effects of synthesis temperature/time on $\mathrm{N}_{2} / \mathrm{SF}_{6}$ ideal selectivity of ZSM- 5 zeolite membranes

Based on the above-mentioned discussion, proper intergrowth of small crystals penetrating into the defects/gaps of the large seed layer is the main factor for a successful different-sized seeding method. This requirement depends on both nucleation and crystal grow reactions with the priority of nucleation reactions [28]. Therefore, an optimum variable temperature/time method with a short-term low-temperature initial stage (4 h at 140@C) facilitates the production of zeolite nuclei which can transfer into the defects of the seed layer. The faster growth of these nuclei in every direction during the high-temperature final stage $(8 \mathrm{~h}$ at 180@C) effectively fills the inter-crystalline gaps resulting in the formation of a high-quality zeolite layer.

It is known that the small seeds at the top layer intend to grow faster than those penetrated into the defects at the bottom layer, wherein, zeolite crystals with the highest vertical growth rate with respect to the support surface have the highest probability of survival [5]. Therefore, controlling the rate of crystal growth reactions by adjusting the synthesis temperature/time can effectively increase the likelihood of small internal seeds growing. The slower growth rate of zeolite crystals at the initial stage of the variable temperature method facilitates the nutrition of nuclei/small crystals penetrating into the defects providing them the opportunity to grow enough to fill defects and gaps in the bottom layer [24]. The growth rate of the small seeds on the top of the seed layer then overcome during the high-temperature final stage accelerating crystal growth rate on top, improving the crystal intergrowth and overgrowing by adjacent crystals which dominate the surface of the film. It would be responsible for the higher selectivity [24]. Contrariwise, starting the synthesis at high temperatures, similar to the M9 membrane, favors the faster intergrowth of small seeds on the top which eliminates the nutrition of internal seeds and consequently increases the inter-crystalline gaps and membrane thickness simultaneously [5, 29]. However, understanding the effect of synthesis conditions (particularly synthesis temperature and time) on growth competition between small crystals on the top of the seed layer and those stuck into the defects/gaps still need to be studied in detail. 


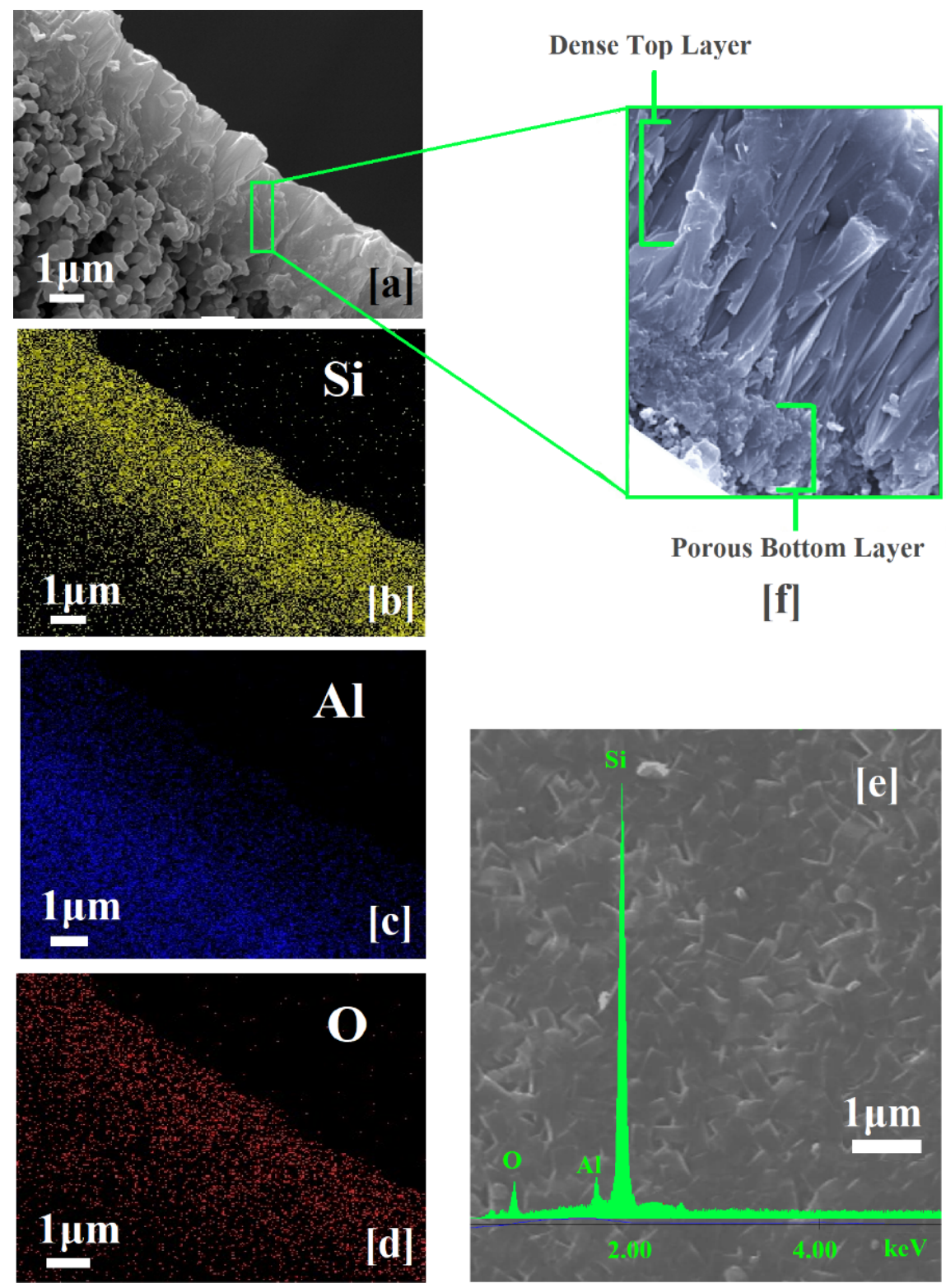

Fig. 9: Elemental mapping for $\mathrm{Si}(\mathrm{b}), \mathrm{Al}(\mathrm{c})$, and $\mathrm{O}$ (d) of the cross-section, and the $\mathrm{Si} / \mathrm{Al}$ ratio of the membrane surface (e) of the M14 sample prepared in this work by EDAX spectrum quantification technique

The EDX elemental mapping for $\mathrm{Si}, \mathrm{Al}$, and $\mathrm{O}$ of the cross-section and the $\mathrm{Si} / \mathrm{Al}$ ratios of the surface of the best ZSM-5 zeolite membrane prepared in this work (M14 membrane) are shown in Fig. 9. It can be found from Fig. 9 that the $\mathrm{Si} / \mathrm{Al}$ ratio of the membrane surface reached 50, reflecting that despite the low $\mathrm{Si} / \mathrm{Al}$ ratio of initial synthesis solution ( 160) a part of the alumina from the support (as aluminate ions) dissolves in the synthesis solution and is incorporated into the framework of zeolite layer during the secondary growth method [22]. Nevertheless, as it is well known that the hydrophilicity of a zeolite membrane strongly depends on the $\mathrm{Si} / \mathrm{Al}$ ratio of zeolite layer, the ZSM-5 membranes prepared in this work still could be used for organic/water separation process by pervaporation technique.

\section{4. $\mathrm{H}_{2} / \mathrm{CO}_{2}$ gas separation tests}


In order to further evaluate the effects of the proposed different-sized seeding in combination with variable temperature/time method on the quality of tubular ZSM-5 zeolite membranes, the gas separation tests using $\mathrm{H}_{2} / \mathrm{CO}_{2}$ binary mixture were utilized at room temperature. We selected four membranes to study ho $\mathrm{w}$ these methods improve in membrane quality. The membranes M3, M7, M9, and M14 as representative of the single-layer, dual-layer, triple-layer, and variable temperature/time methods were selected, respectively. The results of $\mathrm{H}_{2} / \mathrm{CO}_{2}$ separation tests are shown in Fig. 10.

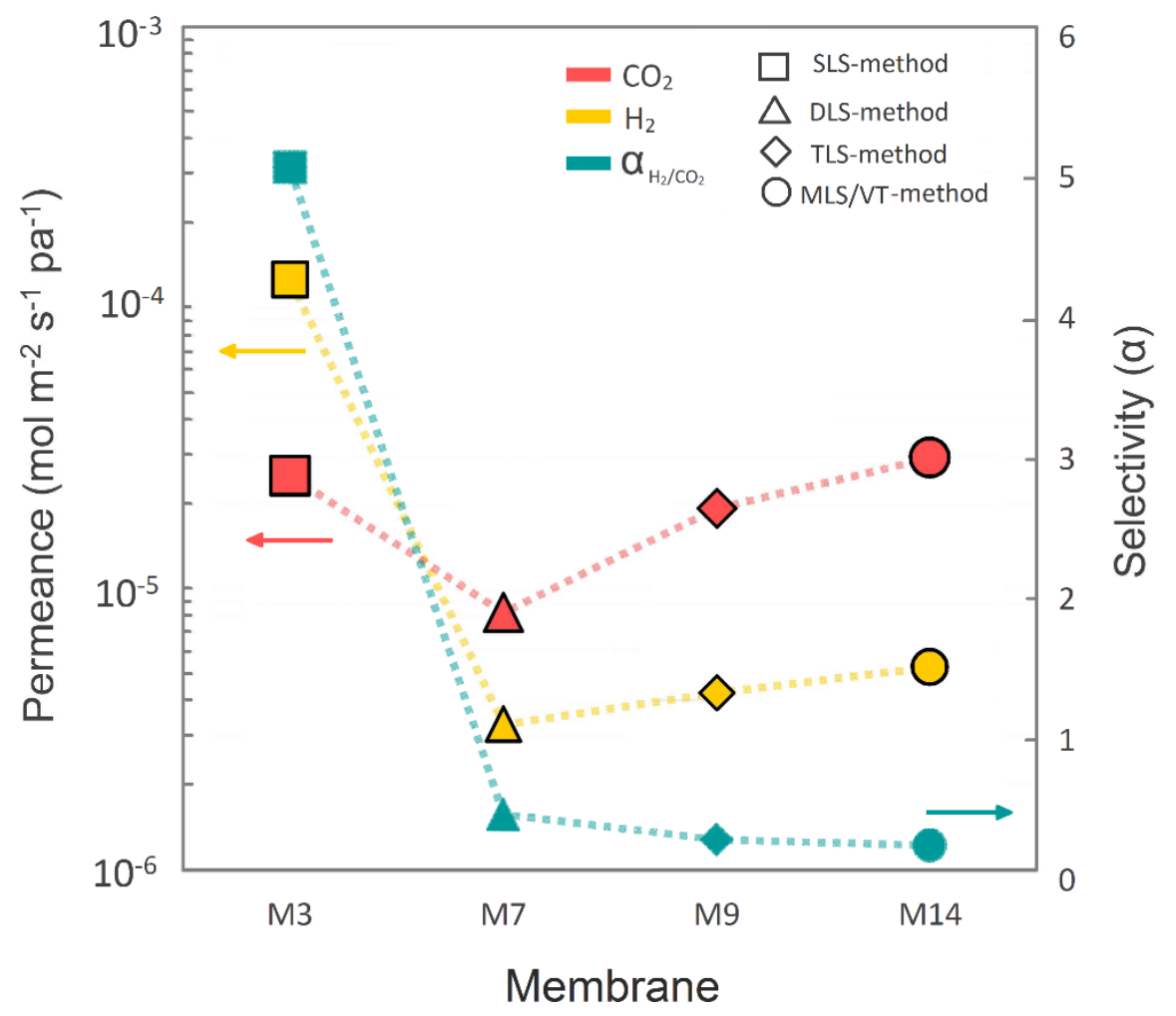

Fig. 10: Effect of the hybrid different-sized seeding/varying-temperature method on gas permeation and selectivity obtained from $\mathrm{H}_{2} / \mathrm{CO}_{2}$ binary mixture

It is known that the high-quality ZSM-5 zeolite membranes with few non-zeolitic pores generally show $\mathrm{H}_{2} / \mathrm{CO}_{2}$ selectivities lower than 1.0 at ambient temperature [30]. The reversed selectivity for $\mathrm{CO}_{2}$ is due to the fact that $\mathrm{CO}_{2}$ preferentially adsorbs in the ZSM-5 zeolite pores and blocks the diffusion channels for $\mathrm{H}_{2}$. The higher the membrane quality, the lower the $\mathrm{H}_{2} / \mathrm{CO}_{2}$ selectivity. However, in low-quality membranes, both $\mathrm{H}_{2}$ and $\mathrm{CO}_{2}$ molecules can transport through inter-crystalline gaps under the Knudsen diffusion mechanism increasing $\mathrm{H}_{2} / \mathrm{CO}_{2}$ selectivities in the reverse trend up to Knudsen selectivity, which makes the membrane more selective for $\mathrm{H}_{2}$, due to its lower molecular weight [31].

The results in Fig. 10 indicate that the $\mathrm{CO}_{2}$ permeances are higher than that of $\mathrm{H}_{2}$ in $\mathrm{M} 7$, M9, and M14 membranes due to the strong adsorption of $\mathrm{CO}_{2}$ in the zeolite pores resulting in $\mathrm{H}_{2} / \mathrm{CO}_{2}$ selectivities lower than Knudsen selectivity. This confirms that using the different-sized seeding method significantly reduces the inter-crystalline gaps making the ZSM- 5 zeolite membranes selective to $\mathrm{CO}_{2}$. In contrast, the $\mathrm{H}_{2} / \mathrm{CO}_{2}$ selectivity of the M3 membrane is almost equal to Knudsen selectivity (4.7) at room temperature showing that the single-layer seed membranes are selective to $\mathrm{H}_{2}$. The results reveal also that both $\mathrm{CO}_{2}$ and $\mathrm{H}_{2}$ permeances for membrane M14 are higher than those for membrane M9. Since these two membranes were synthesized by the same seeding method, the results confirm that the inter-crystalline gaps reduced effectively using the variable temperature/time method due to the elimination of non-zeolitic pores through 
in-situ balancing nucleation and crystal growth reaction rates.

Table 6 compares the $\mathrm{H}_{2} / \mathrm{CO}_{2}$ separation performance of the ZSM-5 zeolite membranes prepared in this work with some of the best performing membranes reported in the literature. As can be seen, membranes synthesized in this work show the best reported MFI-type zeolite membranes in the literature so far, if both selectivity and permeance are taken into account. It proves that using the proposed different-sized seeding method in combination with the variable temperature/time profile, the membrane microstructure improves, the density of the membrane layer increases and the effective membrane thickness decreases. It makes these membranes a proper option for future scale-up applications of tubular zeolite membranes.

Table 6: The $\mathrm{H}_{2} / \mathrm{CO}_{2}$ separation properties of the ZSM-5 zeolite membranes

\begin{tabular}{|c|c|c|c|c|c|c|}
\hline $\begin{array}{l}\text { Support } \\
\text { material/shape }\end{array}$ & $\begin{array}{l}\mathrm{H}_{2} / \mathrm{CO}_{2} \text { feed } \\
\text { composition } \\
\text { (mol/mol) }\end{array}$ & $\begin{array}{l}\text { Temperature } \\
\left({ }^{\circ} \mathrm{C}\right)\end{array}$ & $\begin{array}{l}\text { Transmembrane } \\
\text { pressure }(\mathrm{kPa})\end{array}$ & $\begin{array}{l}\mathrm{CO}_{2} \\
\text { permeance } \\
\times 10^{-7}(\mathrm{~mol} \\
\left.\mathrm{m}^{-2} \mathrm{~s}^{-1} \mathrm{~Pa}^{-1}\right)\end{array}$ & $\begin{array}{l}\mathrm{H}_{2} / \mathrm{CO}_{2} \\
\text { selectivity }\end{array}$ & Reference \\
\hline $\begin{array}{l}\alpha- \\
\text { alumina/disc }\end{array}$ & $70 / 30$ & 80 & 140 & 16.9 & 2.16 & {$[32]$} \\
\hline $\begin{array}{l}\alpha- \\
\text { alumina/disc }\end{array}$ & $50 / 50$ & 27 & 300 & 0.9 & 0.17 & {$[33]$} \\
\hline $\begin{array}{l}\alpha- \\
\text { alumina/disc }\end{array}$ & $50 / 50$ & 25 & 90 & 120 & 1.75 & {$[34]$} \\
\hline $\begin{array}{l}\alpha- \\
\text { alumina/disc }\end{array}$ & $50 / 50$ & 22 & 90 & 13 & 0.40 & {$[35]$} \\
\hline $\begin{array}{l}\alpha- \\
\text { alumina/disc }\end{array}$ & $50 / 50$ & 25 & 100 & 1.9 & 0.30 & {$[34]$} \\
\hline $\begin{array}{l}\text { Stainless- } \\
\text { steel/wafer }\end{array}$ & $50 / 50$ & 20 & 100 & 7 & 0.07 & {$[36]$} \\
\hline $\begin{array}{l}\text { Stainless- } \\
\text { steel/disc }\end{array}$ & $50 / 50$ & 27 & 100 & 2.2 & 0.08 & {$[37]$} \\
\hline $\begin{array}{l}\alpha \text {-alumina/ } \\
\text { YSZ/disc }\end{array}$ & $50 / 50$ & 27 & 100 & 1.7 & 0.28 & {$[22]$} \\
\hline $\begin{array}{l}\text { Stainless- } \\
\text { steel/disc }\end{array}$ & $50 / 50$ & 22 & 100 & 3.8 & 0.08 & {$[38]$} \\
\hline $\begin{array}{l}\alpha \text {-alumina } \\
\text { /hollow fiber }\end{array}$ & $50 / 50$ & 450 & & 5.56 & 10.0 & {$[39]$} \\
\hline $\begin{array}{l}\alpha \text {-alumina / } \\
\text { hollow fiber }\end{array}$ & $50 / 50$ & 27 & 100 & 25 & 0.44 & {$[10]$} \\
\hline $\begin{array}{l}\alpha \text {-alumina } \\
\text { /tubular }\end{array}$ & $50 / 50$ & 25 & 100 & 82 & 0.22 & $\begin{array}{l}\text { This work } \\
\text { (M7) }\end{array}$ \\
\hline $\begin{array}{l}\alpha \text {-alumina } \\
\text { /tubular }\end{array}$ & $50 / 50$ & 25 & 100 & 193 & 0.18 & $\begin{array}{l}\text { This work } \\
\text { (M9) }\end{array}$ \\
\hline $\begin{array}{l}\alpha \text {-alumina } \\
\text { /tubular }\end{array}$ & $50 / 50$ & 25 & 100 & 292 & 0.11 & $\begin{array}{l}\text { This work } \\
\text { (M14) }\end{array}$ \\
\hline
\end{tabular}

\section{Conclusion}

High-quality ZSM-5 zeolite membranes can be synthesized on the $\alpha$-alumina supports by applying a novel hybrid secondary growth method consisting of different-sized seeding in combination with the variable temperature/time profile. Using this method, the selectivity and permeance of the membrane are increased via minimizing the defects/inter-crystalline gaps and reducing the effective thickness of the membrane (reducing the mass transfer resistance), respectively. The microstructure of membranes can be manipulated by the 
different-sized seeding method resulting in a thin, fully inter-grown, and dense layer on the top, and a porous layer at the bottom resulting in a significant increase in selectivity without scarifying the permeance. It was found also that changing the seed size at the bottom layer, mainly influence membrane permeance, while changing seed size on top, mainly affects selectivity. Using the variable temperature/time method further eliminates the inter-crystalline gaps/defects via balancing the nucleation and grow reaction rates during the secondary growth synthesis.

\section{References}

[1] M. Mirfendereski, M. Sadrzadeh, T. Mohammadi, Effect of synthesis parameters on single gas permeation through T-type zeolite membranes, Int. J. Greenh. Gas Con. 2 (2008) 531-538. https://doi.org/10.1016/j.ijggc.2008.03.001.

[2] D.W. Shin, S.H. Hyun, C.H. Cho, M.H. Han, Synthesis and $\mathrm{CO}_{2} / \mathrm{N}_{2}$ gas permeation characteristics of ZSM-5 zeolite membranes, Micropor. Mesopor. Mater. 85 (2005) 313-323. https://doi.org/10.1016/j.micromeso.2005.06.035.

[3] M. Grahn, J. Hedlund, Maxwell-Stefan modeling of high flux tubular silicalite-1 membranes for $\mathrm{CO}_{2}$ removal from $\mathrm{CO}_{2} / \mathrm{H}_{2}$ gas mixtures, J. Membrane Sci. 471 (2014) 328-337. https://doi.org/10.1016/j.memsci.2014.08.034.

[4] D.M. D'Alessandro, B. Smit, J.R. Long, Carbon dioxide capture: prospects for new materials, Angew. Chem. Int. Edit. 49 (2010) 6058-6082. https://doi.org/10.1002/anie.201000431.

[5] S. Gopalakrishnan, T. Yamaguchi, S.-i. Nakao, Permeation properties of templated and template-free ZSM-5 membranes, J. Membrane Sci. 274 (2006) 102-107. https://doi.org/10.1016/j.memsci.2005.08.005.

[6] S.M. Mirfendereski, Development of a multi-step hybrid method to synthesize highly-permeable and well-oriented SAPO-34 membranes for $\mathrm{CO}_{2}$ removal applications, Chem. Eng. Sci. 208 (2019) 115157. https://doi.org/10.1016/j.ces.2019.115157.

[7] J.C. Poshusta, R.D. Noble, J.L. Falconer, Temperature and pressure effects on $\mathrm{CO}_{2}$ and $\mathrm{CH}_{4}$ permeation through MFI zeolite membranes, J. Membrane Sci. 160 (1999) 115-125. https://doi.org/10.1016/S03767388(99)00073-3.

[8] E. Hayakawa, S. Himeno, Synthesis and Characteristics of Al-containing ZSM-58 Zeolite Membrane for $\mathrm{CO}_{2}$ Separation, Int. J. Chem. Eng. Appl. 11 (2020). https://doi.org/ 10.18178/ijcea.2020.11.1.771.

[9] Z. Zhang, M.H. Ibrahim, M.H. El-Naas, J. Cai, Zeolites nanocomposite membrane applications in $\mathrm{CO}_{2}$ capture, Handbook of Nanomaterials for Industrial Applications, Elsevier, 2018, pp. 916-921.

[10] C.H. Chen, L. Meng, K.L. Tung, Y. Lin, Effect of substrate curvature on microstructure and gas permeability of hollow fiber MFI zeolite membranes, AIChE J. 64 (2018) 3419-3428. https://doi.org/10.1002/aic.16197.

[11] X. Zhang, H. Liu, K.L. Yeung, Influence of seed size on the formation and microstructure of zeolite silicalite-1 membranes by seeded growth, Mater. Chem. Phys. 96 (2006) 42-50. https://doi.org/10.1016/j.matchemphys.2005.06.031.

[12] S. Xia, Y. Peng, Z. Wang, Microstructure manipulation of MFI-type zeolite membranes on hollow fibers for ethanol-water separation, J. Membrane Sci. 498 (2016) 324-335. https://doi.org/10.1016/j.memsci.2015.10.024.

[13] L. Shan, J. Shao, Z. Wang, Y. Yan, Preparation of zeolite MFI membranes on alumina hollow fibers with high flux for pervaporation, J. Membrane Sci. 378 (2011) 319-329. https://doi.org/10.1016/j.memsci.2011.05.011.

[14] Y. Li, X. Zhang, J. Wang, Preparation for ZSM-5 membranes by a two-stage varying-temperature synthesis, Sep. Purif. Technol. 25 (2001) 459-466. https://doi.org/10.1016/S1383-5866(01)00075-2. 
[15] C. Kong, J. Lu, J. Yang, J. Wang, Preparation of silicalite-1 membranes on stainless steel supports by a two-stage varying-temperature in situ synthesis, J. Membrane Sci. 285 (2006) 258-264. https://doi.org/10.1016/j.memsci.2006.08.027.

[16] M. Abbasi, M. Mirfendereski, M. Nikbakht, M. Golshenas, T. Mohammadi, Performance study of mullite and mullite-alumina ceramic MF membranes for oily wastewaters treatment, Desalination 259 (2010) 169178. https://doi.org/10.1016/j.desal.2010.04.013.

[17] Y. Peng, H. Lu, Z. Wang, Y. Yan, Microstructural optimization of MFI-type zeolite membranes for ethanol-water separation, J. Mater. Chem. A 2 (2014) 16093-16100. https://doi.org/10.1039/C4TA02837F.

[18] F. Banihashemi, L. Meng, A.A. Babaluo, Y. Lin, Xylene vapor permeation in MFI zeolite membranes made by templated and template-free secondary growth of randomly oriented seeds: Effects of xylene activity and microstructure, Ind. Eng. Chem. Res. 57 (2018) 16059-16068. https://doi.org/10.1021/acs.iecr.8b01373.

[19] M. Mirfendereski, T. Mohammadi, Investigation of hydrothermal synthesis parameters on characteristics of $\mathrm{T}$ type zeolite crystal structure, Powder Technol. 206 (2011) 345-352. https://doi.org/10.1016/j.powtec.2010.10.003.

[20] R. Cai, Y. Liu, S. Gu, Y. Yan, Ambient pressure dry-gel conversion method for zeolite MFI synthesis using ionic liquid and microwave heating, J. Am. Chem. Soc. 132 (2010) 12776-12777. https://doi.org/10.1021/ja101649b.

[21] J. Li, C. Shi, H. Zhang, X. Zhang, Y. Wei, K. Jiang, B. Zhang, Silicalite-1 zeolite membrane: Synthesis by seed method and application in organics removal, Chemosphere 218 (2019) 984-991. https://doi.org/10.1016/j.chemosphere.2018.11.215.

[22] H. Wang, Y. Lin, Effects of water vapor on gas permeation and separation properties of MFI zeolite membranes at high temperatures, AIChE J. 58 (2012) 153-162. https://doi.org/10.1002/aic.12622.

[23] Q. Li, D. Creaser, J. Sterte, The nucleation period for TPA-silicalite-1 crystallization determined by a two-stage varying-temperature synthesis, Micropor. Mesopor. Mater. 31 (1999) 141-150. https://doi.org/10.1016/S1387-1811(99)00064-5.

[24] X.-L. Zhang, M.-H. Zhu, R.-F. Zhou, X.-S. Chen, H. Kita, Synthesis of a silicalite zeolite membrane in ultradilute solution and its highly selective separation of organic/water mixtures, Ind. Eng. Chem. Res. 51 (2012) 11499-11508. https://doi.org/10.1021/ie300951e.

[25] W.C. Wong, L.T.Y. Au, C.T. Ariso, K.L. Yeung, Effects of synthesis parameters on the zeolite membrane growth, J. Membrane Sci. 191 (2001) 143-163. https://doi.org/10.1016/S0376-7388(01)00453-7.

[26] C. Kong, J. Lu, J. Yang, J. Wang, Catalytic dehydrogenation of ethylbenzene to styrene in a zeolite silicalite-1 membrane reactor, J. Membrane Sci. 306 (2007) 29-35. https://doi.org/10.1016/j.memsci.2007.08.018.

[27] H. Wang, T.J. Pinnavaia, MFI zeolite with small and uniform intracrystal mesopores, Angew. Chem. Int. Edit. 45 (2006) 7603-7606. https://doi.org/10.1002/ange.200602595.

[28] Z. Wang, I. Kumakiri, K. Tanaka, X. Chen, H. Kita, NaY zeolite membranes with high performance prepared by a variable-temperature synthesis, Micropor. Mesopor. Mater. 182 (2013) 250-258. https://doi.org/10.1016/j.micromeso.2013.05.002.

[29] M. Kanezashi, J. O'Brien, Y. Lin, Template-free synthesis of MFI-type zeolite membranes: permeation characteristics and thermal stability improvement of membrane structure, J. Membrane Sci. 286 (2006) 213-222. https://doi.org/10.1016/j.memsci.2006.09.038.

[30] X. Zhu, H. Wang, Y. Lin, Effect of the membrane quality on gas permeation and chemical vapor deposition modification of MFI-type zeolite membranes, Ind. Eng. Chem. Res. 49 (2010) 10026-10033. 
https://doi.org/10.1021/ie101101z.

[31] Y. Zhang, Q. Sun, X. Gu, Pure $\mathrm{H}_{2}$ production through hollow fiber hydrogen-selective MFI zeolite membranes using steam as sweep gas, AIChE J. 61 (2015) 3459-3469. https://doi.org/10.1002/aic.14924.

[32] S.K. Wirawan, D. Creaser, J. Lindmark, J. Hedlund, I.M. Bendiyasa, W.B. Sediawan, $\mathrm{H}_{2} / \mathrm{CO}_{2}$ permeation through a silicalite-1 composite membrane, J. Membrane Sci. 375 (2011) 313-322. https://doi.org/10.1016/j.memsci.2011.03.061.

[33] M. Kanezashi, Y. Lin, Gas permeation and diffusion characteristics of MFI-type zeolite membranes at high temperatures, J. Phys. Chem. C 113 (2009) 3767-3774. https://doi.org/10.1021/jp804586q.

[34] J. Lindmark, J. Hedlund, S.K. Wirawan, D. Creaser, M. Li, D. Zhang, X. Zou, Impregnation of zeolite membranes for enhanced selectivity, J. Membrane Sci. 365 (2010) 188-197. https://doi.org/10.1016/j.memsci.2010.09.006.

[35] J. Lindmark, J. Hedlund, Modification of MFI membranes with amine groups for enhanced $\mathrm{CO}_{2}$ selectivity, J. Mater. Chem. 20 (2010) 2219-2225. https://doi.org/10.1039/B919242E.

[36] H. Guo, G. Zhu, H. Li, X. Zou, X. Yin, W. Yang, S. Qiu, R. Xu, Hierarchical growth of large-scale ordered zeolite silicalite-1 membranes with high permeability and selectivity for recycling $\mathrm{CO}_{2}$, Angew. Chem. Int. Edit. 45 (2006) 7053-7056. https://doi.org/10.1002/anie.200602308.

[37] F. Kapteijn, W. Bakker, J. Van De Graaf, G. Zheng, J. Poppe, J. Moulijn, Permeation and separation behaviour of a silicalite-1 membrane, Catal. Today 25 (1995) 213-218. https://doi.org/10.1016/09205861(95)00078-T.

[38] W.J. Bakker, F. Kapteijn, J. Poppe, J.A. Moulijn, Permeation characteristics of a metal-supported silicalite-1 zeolite membrane, J. Membrane Sci. 117 (1996) 57-78. https://doi.org/10.1016/03767388(96)00035-X.

[39] W. Yuan, D. Wang, L. Li, MFI-type zeolite membrane on hollow fiber substrate for hydrogen separation, Chinese Sci. Bull. 56 (2011) 2416-2418. https://doi.org/10.1007/s11434-011-4599-4. 